\title{
SUBJETIVIDADE E TECNOLOGIA
}

\section{Pedro Goergen}

Quando falamos em ciência \& tecnologia, pensamos em produtos e eventos contemporâneos. Pensamos em máquinas, computadores, performance, em precisão, velocidade. Pensamos em coisas que potencializam a ação humana e que facilitam a vida. Esquecemos que ciência \& tecnologia é um projeto muito antigo do homem que tem sua origem na necessidade e vontade de ampliação de sua capacidade física. Esta vontade está presente nas comunidades humanas desde os tempos mais remotos e, na verdade, nasceu junto com a cultura. Os chineses, egípcios, gregos e os índios americanos mostraram isso nos mais diferentes domínios do conhecimento e da ação como a filosófica, a matemática, a engenharia, a arquitetura e a astrologia.

Max Horkheimer e Theodor Adorno na Dialética do Esclarecimento e Hanah Arendt na Condição Humana descreveram muito bem este uso da razão pelo homem para o equacionamento dos seus problemas, a proteção contra os perigos, o entendimento dos fenômenos naturais, enfim, a produção e uso dos conhecimentos para o domínio da natureza. Arendt destaca o esforço para aliviar o trabalho fatigante, reduzir o suor do rosto e tornar a vida mais agradável.

Adorno e Horkheimer falam, neste sentido, da vontade do homem de tornarse senhor da terra e descrevem este processo como o processo de emancipação do ser humano. Em termos da cultura ocidental, a primeira expressão desta longa caminhada foram os mitos, transmitidos oralmente de geração em geração pelos gregos antigos e magistralmente sistematizados por Homero na Ilíada e na Odisséia. Os deuses eram figuras que por suas ações e sentimentos forneciam a origem, a explicação e o sentido das coisas, bem como dos medos e sentimentos humanos. 
Alguns séculos mais tarde, insatisfeitos com as explicações míticas, certos físicos e matemáticos procuraram novas explicações, agora baseadas apenas na razão humana e dispensando o auxílio dos deuses. Nascia a filosofia, uma nova forma de conhecimento, do qual os filósofos eram os amigos e mestres. Os pré-socráticos elegiam certas substâncias básicas como a água, o fogo, o ar etc. que consideravam ser a base de toda a realidade e a partir das quais acreditavam poder explicar tudo. Platão condena os deuses, por serem feitos à imagem e semelhança dos homens e, por isso mesmo, serem igualmente plenos de defeitos. Mentirosos e falsos, dizia. Para ele, a realidade sensível é, de fato, um reflexo de uma outra realidade superior, a das idéias, da qual o mundo das experiências sensíveis não é mais que sombra. Aristóteles, talvez o mais influente filósofo de todos os tempos, abandona o idealismo platônico e funda o pensamento científico, cujas bases são a lógica e a metafísica. O pensamento se rege por leis da lógica, e a metafísica diferencia entre matéria e forma de cuja confluência emerge a matéria.
Depois da conquista dos gregos pelos Macedônios na Batalha de Queronéia, do posterior domínio dos romanos, bem como do seu declínio e da ascensão do cristianismo e da Igreja católica como grande força espiritual e política da Idade Média, veio o Renascimento e o Humanismo. Estes movimentos representam o prenúncio de uma nova era: a Modernidade. Nesta, após o longo período teológico medieval, o homem se reconscientiza de suas capacidades racionais e, a partir desta nova fé, se coloca o imenso desafio de desvendar os segredos da natureza como forma de domínio e uso. Ciência é o domínio teórico das leis, tecnologia o aproveitamento prático desse conhecimento. Substitui-se, portanto, a cultura teocêntrica e metafísica por uma cultura secular e antropocêntrica.

Esta nova forma de pensar concretizouse através de pensadores como Roger Bacon (1214-1294) que, separando a teologia das ciências profanas, colocou os três pilares mestres destas últimas: a experiência, o experimento e a matemática. Seguiram-se Copérnico (1473-1543) com sua revolução da imagem do mundo do geocentrismo para 
o heliocentrismo; Francis Bacon, (15611626) empirista inglês, que abriu caminho para a moderna ciência da natureza e conferiu um sentido utilitário ao conhecimento; René Descartes (15961650) que reafirmou e sistematizou a crença no poder da razão como mecanismo de desvendamento dos segredos da natureza que, qual máquina, se movimenta segundo uma lógica imperturbável de leis cujo conhecimento desvendaria todos os seus segredos; Immanuel Kant (1724-1804) acrescentou com seu criticismo o reconhecimento das possibilidades e dos limites da razão.

Assim constitui-se o grande projeto moderno cuja característica central é precisamente a confiança ilimitada na razão. Segundo Kant, a humanidade vive na menoridade por culpa própria, ou seja, porque não saber usar a própria razão. Para alcançar a maioridade basta aprender a usá-la. Portanto: "Sapere aude". Este é o imperativo dos novos tempos que está na origem da ciência \& tecnologia. A conquista do conhecimento trará tempos melhores, aliviará as dores e sofrimentos, melhorará as condições de vida. Enfim, o conhecimento representa garantia de progresso. Esta fórmula - conhecimento é igual a progresso - tornou-se emblemática de uma grande narrativa através da qual a humanidade passaria de um estágio menos desenvolvido para um mais desenvolvido. O progresso colocase como o novo telos da história a ser alcançado pela razão em substituição à salvação eterna atingível apenas pela fé.

Agora, o passado afigura-se como superstição e ignorância. Hegel (17701831) dizia que vivemos um novo tempo cujo marco e simbologia maiores encontram-se na Revolução Francesa. O homem, finalmente, sentia-se no caminho do progresso, começava a entrever a possibilidade de tornar-se senhor da história. De ninguém mais senão dele dependeria esta conquista desde sempre desejada. Tudo era esperança, tudo era promessa, tudo era luz. Não por acaso este período passou a ser conhecido como Iluminismo.

Ser senhor é ser dominador e livre. A Modernidade busca instaurar a inédita união entre razão e liberdade. A razão torna-se a nova força pela qual o homem pode intervir não só no mundo natural, mas também no mundo social. Além de ser um atributo do ser 
individual, a razão é alçada à capacidade de sujeito-espécie de promover a emancipação do homem através da ciência e da tecnologia.

No entanto, sob a empolgação dos enormes sucessos, sobretudo materiais, paulatinamente o conceito de razão foi sofrendo um processo de estreitamento e redução à sua dimensão científica nos termos cartesianos, ou seja, verdadeiramente racionais passaram a ser apenas os conhecimentos exatos e seguros, segundo os padrões da lógica matemática. Em outros termos, o conceito de ciência foi sendo reduzido cada vez mais ao tipo de conhecimentos auferidos pela ciências naturais e exatas, particularmente aqueles com perspectiva de aplicação prática, ou seja conhecimentos com possibilidade de aplicação tecnológica. A racionalidade científica torna-se o padrão que, associado à dimensão da utilidade, agrega poder ao conhecimento. $\mathrm{O}$ conceito de salvação ou, como se dirá agora, de emancipação passa a referir-se apenas à dimensão secular e material.

Um outro aspecto que caracteriza a passagem da Idade Média para a Moderna é o abandono da idéia de comunidade, de povo de Deus e a ocupação de seu lugar pela idéia de individualidade e subjetividade. $\mathrm{O}$ esforço de emancipação tem como fundamento o indivíduo e seus direitos, tornando-se a 'subjetividade' o preceito fundamental da Modernidade. Lembremos Descartes (1596-1650) com seu 'cogito ergo sum': a certeza última do conhecimento fica reduzida à interioridade subjetiva do indivíduo. $\mathrm{O}$ sujeito cognoscente assume poder instituinte de uma nova realidade em substituição à antiga visão mágica e metafísica. Sobre estas novas bases, adensa-se o projeto de que ciência \& tecnologia levariam o homem a um novo patamar de emancipação e liberdade.

Mas nem tudo é luz nessa utopia designada esclarecimento ou iluminismo. Muito cedo, pensadores como Nietzsche, Heidegger, Foucault, Bataille, Lyotard, Horkheimer, Adorno, dentre muitos outros, fizeram-lhe severas críticas. O principal alvo dessas críticas é o conceito de progresso, suposto fundamental de todo o projeto moderno. Kant deixara muito clara a sua convicção de que, se soubessemos usar a nossa razão, estaríamos, enquanto 
indivíduos e enquanto sociedade, caminhando para um mundo melhor. Kant não contara com a drástica redução do conceito de razão. O filósofo alemão ainda tinha em mente um conceito amplo e integral de razão que envolvia tanto o aspecto do conhecimento teórico/científico quanto $\mathrm{o}$ aspecto prático/moral e estético/expressivo. Neste sentido, as três críticas de Kant (Crítica da Razão pura, Crítica da razão prática e Crítica do juízo) devem ser lidas em conjunto. O que ocorreu de fato foi uma leitura unilateral que privilegiou o lado cognitivo nos termos que referi acima. O homem moderno jogou todas as suas cartas na ciência \& tecnologia, convencido de que era este o caminho seguro do progresso. Os críticos que mencionei tentam mostrar precisamente que esta esperança não se realizou. $\mathrm{O}$ argumento não é outro senão a descrição da trágica realidade do mundo em que vivemos com a pergunta aos que colocaram toda sua esperança na razão instrumental se este é o progresso que haviam imaginado.

Adorno e Horkheimer descrevem de forma lapidar esta paradoxal realidade de hoje em que convivem, lado a lado, o mais alto desenvolvimento científico/tecnológico alcançado pela humanidade com um grau não menos elevado de miséria, fome, desemprego, de poluição e destruição ambiental. "A terra totalmente esclarecida resplandece sob o signo de uma calamidade triunfal". Também Walter Benjamin nos legou, na forma de uma alegoria, o mesmo alerta. Ao descrever uma pintura de Paul Klee que representa um anjo estilizado, diz que este anjo parece o anjo da história sobre o qual sopra uma brisa que se aninha em suas asas abertas que já não se podem fechar empurrando-o para trás, enquanto seus olhos esbugalhados de espanto vêem as ruínas que sobre ruínas se amontoam aos seus pés. Este vento que empurra o anjo da história de costas para o futuro, assim Benjamin, é o que chamamos de progresso.

No céu da esperança de liberdade e autonomia, anunciada na modernidade, pairam escuras nuvens de uma nova servidão: não só a natureza tornou-se um objeto de manipulação, exploração e destruição, mas o próprio ser humano não escapou às ambições da razão instrumental, agora dominado, também ele, como objeto de manipulação e 
exploração. A razão emancipadora transforma-se em razão instrumental que, servindo-se dos mesmos mecanismos da ciência e tecnologia, não se detém ante o próprio homem, objetalizazando-o e mercantilizando-o. Esta objetalização do ser humano o ameaça em sua liberdade e subjetividade, o domina e o conduz a uma nova servidão.

Utilidade e eficiência, como já disse acima, tornam-se os mandamentos maiores da nova racionalidade. A forma de racionalidade que passa a ser considerada certa e segura, separa-se e distancia-se daquelas outras dimensões da razão que abrangem as decisões práticas (ético-morais) e as estéticas que requerem a explicação e a consistência interior dos sistemas de valor para a fundamentação dos atos de decisão. A racionalidade técnica (com suas prerrogativas de utilidade, eficiência, segurança, previsibilidade e, mais recentemente, de interesse mercadológico) ocupa e reduz o espaço humano.

A subjetividade e a individualidade, duas das grandes prerrogativas do projeto moderno da salvação pela ciência e tecnologia, ameaçam sucumbir ante a instrumentalização e unilateralização do humano. Esta ameaça torna-se particularmente forte no contexto da globalização em que a subjetividade, individualidade e identidade tornam-se, mais e mais, permeáveis a imposições comandadas por interesses técnicosistêmicos que pouco têm a ver com os interesses genuinamente humanos. As estratégias dos interesses instrumentais perpassam toda a cultura globalizada e ameaçam uniformizar a multidimensionalidade da subjetividade humana que é muito mais ampla que sua face operacional e instrumental, esquecendo ou relegando a um plano secundário o lado ético e estético do humano.

Ciência e tecnologia alimentam e mantêm funcionando uma máquina que se torna autônoma e substitui o próprio ser humano. O pensamento transformase em processo matemático que resulta no técnico que, por sua vez, coisifica o sujeito, suprime a consciência e dilui a subjetividade. Lembro novamente uma passagem de Adorno: "O eu integralmente capturado pela civilização 
reduz-se a um elemento dessa inumanidade, à qual, desde o início, a humanidade procurou escapar. Concretiza-se, assim, o mais antigo medo, o medo da perda do próprio nome".

São estas idéias pessimistas, contrárias à ciência e tecnologia? Longe disso! São apenas alertas necessários e urgentes contra o encantamento pela ciência e tecnologia como um novo mito, como um novo deus, capaz de resolver todos os problemas humanos e realizar todos os seus anseios. Alertas contra o 'rebanhamento' e isolamento dos seres humanos que os torna desprovidos de sentido interior, insensíveis aos problemas do humano, incapazes de construir utopias sociais. Alertas contra a absolutização da razão instrumental, calculista, operacional e utilitarista que transforma o ser humano em mercadoria.

A subjetividade é o núcleo da autonomia, da reflexão, da avaliação e julgamento que é preciso ser preservado se não quisermos sacrificar no altar da ciência \& tecnologia o próprio homem. É preciso que a educação, entendida como o processo de socialização e individuação/subjetivação das novas gerações, encontre formas para contribuir para a formação de um ser humano integral, autônomo e reflexivo. Este, poderíamos dizer, é um dos grandes dilemas e desafios da atualidade: formar um ser humano crítico e negador (da realidade que o quer anular) ou formar um indivíduo adaptado, a-crítico e afirmador. Formar um ser humano interpelador, capaz não só de absorver as influências, mas de colocá-las numa tela reflexiva que lhe permita avaliá-las, rejeitá-las ou integrálas seletiva e conscientemente. Sujeitos interpeladores são sujeitos autônomos, capazes de resistir ao sistema, negar a ideologia dominante que se infiltra por todos os poros e condiciona os próprios sentidos. Sem este ideal nos rendemos, abrimos mão de nós mesmos como seres capazes de escrever nossa própria biografia e conduzir nossa história.

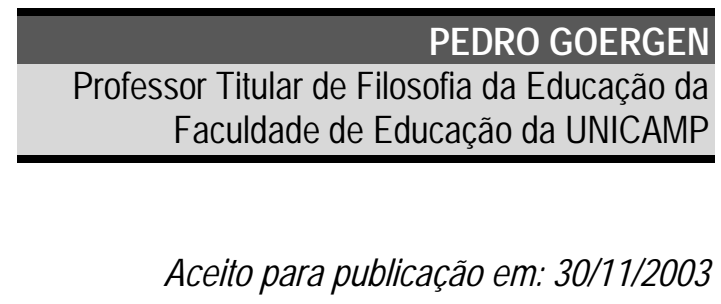

Aceito para publicação em: 30/11/2003 